downloads/MedicalDevices/Safety/AlertsandNotices/ PublicHealthNotifications/ucm063115.pdf. Accessed October 8, 2010.

2. US Congress. Needlestick safety and prevention act. HR 5178 . Washington, DC: Government Printing Office, 2000. http:// frwebgate.access.gpo.gov/cgi-bin/getdoc.cgi?dbname $=106$ _cong_public_laws\&docid = f:publ430.106.

3. Rupp M, Sholtz L, Jourdan D, et al. Outbreak of bloodstream infection temporally associated with the use of an intravascular needleless valve. Clin Infect Dis 2007;44:1408-1414.

4. Field K, McFarlane $C$, Cheng A, et al. Incidence of catheterrelated bloodstream infection among patients with a needleless, mechanical valve-based intravenous connector in an Australian hematology-oncology unit. Infect Control Hosp Epidemiol 2007; 28:610-613.

5. Maki DG, Kluger DM, Crnich CJ. The risk of bloodstream infection in adults. Mayo Clin Proc 2006;81(9):1159-1171.

6. Maragakis L, Bradley $\mathrm{K}$, Song $\mathrm{X}$, et al. Increased catheter-related bloodstream infection rates after the introduction of a new mechanical valve intravenous access port. Infect Control Hosp Epidemiol 2006;27:67-70.

7. Toscano CM, Bell M, Zukerman C. Gram-negative bloodstream infections in hematopoetic stem cell transplant patients: the roles of needleless device use, bathing practices, and catheter care. Am I Infect Control 2009;37(4):327-334.

8. Salgado CD, Chinnes L, Paczesny TH, Cantey JR. Increased rate of catheter-related bloodstream infection associated with use of a needleless mechanical valve device at a long-term acute care hospital. Infect Control Hosp Epidemiol 2007;28:684-688.

9. Ryder M, Fisher S, Hamilton G, et al. Bacterial transfer through needlefree connectors: comparison of nine different devices. In: Program and abstracts of the 17th Annual Scientific Meeting of the Society for Healthcare Epidemiology of America; April 1417, 2007; Baltimore, MD, 2007. Abstract 210.

10. Menyhay SZ, Maki DG. Disinfection of needleless catheter connectors and access ports with alcohol may not prevent microbial entry: the promise of a novel antiseptic-barrier cap. Infect Control Hosp Epidemiol 2006;27:23-27.

\section{Cost-Effectiveness of Universal Screening of Healthy Newborns for Nasal Methicillin- Resistant Staphylococcus aureus Colonization at Birth}

To the Editor-Community-associated methicillin-resistant Staphylococcus aureus (CA-MRSA) infections are increasing in frequency and are an emerging problem among pregnant

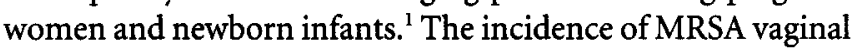
colonization among pregnant women usually ranges from $0.5 \%$ to $3.5 \%{ }^{2,3}$ However, in a recent study of pregnant women in Tennessee, $10.5 \%$ of genital swab specimens submitted for routine screening for Group B beta-hemolytic streptococcus also tested positive for MRSA. ${ }^{4}$ MRSA colo- nization is a risk factor for nosocomial transmission and subsequent MRSA infection. The incidence and consequence of MRSA colonization among newborn infants is not well characterized.

Our institution, a 571-bed tertiary care academic institution, is a state-designated perinatal center that serves 8 regional hospitals. We have approximately 1,400 deliveries per year. Since December 2007, our institution has conducted universal surveillance of all patients for nasal MRSA colonization upon admission to the hospital. However, the costeffectiveness of universal surveillance for MRSA colonization among healthy newborn infants is not known. We analyzed our data to determine the incidence of nasal MRSA colonization among newborn infants at birth and the cost-effectiveness of universal MRSA screening of healthy term newborns.

All newborn infants born between December 1,2007, and August 31, 2009, were screened at birth for nasal MRSA colonization using the GeneXpert System and the Xpert MRSA real-time PCR test kit (Cepheid). The cost of MRSA screening testing was obtained from the microbiology laboratory. The transmission rate of MRSA was calculated based on published estimates by Jernigan et al $^{5}$ of 0.14 patient-per-day rate of transmission for an unrecognized newborn who has been colonized and 0.009 for a recognized newborn who has been colonized in isolation precautions. ${ }^{5}$ Illinois Public Act 0950312 mandates MRSA screening for all patients admitted to an intensive care unit (ICU) as well as patients admitted to non-ICU settings deemed to be at high risk for MRSA carriage. ${ }^{6}$ Therefore, only screening costs of children admitted to the newborn nursery who would not be tested under the legislative mandate were included in the cost analysis. Microbiology laboratory data were also reviewed to detect any invasive MRSA infections in newborns less than 48 hours of age.

During the study period, 2,110 children were born, and 2,031 (96\%) infants underwent MRSA screening at birth. Overall, 4 of $2,031(0.2 \%)$ infants tested positive for nasal MRSA colonization. A total of 520 babies were excluded from the cost analysis because they were admitted to the neonatal ICU, either from labor and delivery or from the newborn nursery, and thus would have been tested for MRSA colonization under our state mandate. Similarly, 2 of 4 infants who tested positive for MRSA colonization were born prematurely and required NICU care; they were not included in the cost analysis.

The total cost of screening of 1,582 newborns who were admitted to and stayed in the newborn nursery was $\$ 79,100$ at $\$ 50$ per test for our healthcare system, and for payers, the cost was $\$ 316,400$ at $\$ 200$ per test. Thus, the cost of detection of a carrier was $\$ 39,550$ for our healthcare system and $\$ 158,200$ for payers. The study period was 3,348 patient-days, with an average length of stay of 2.1 days in our nursery. The 2 newborns who had been colonized stayed for a total of 3 
days in the hospital. Based on the transmission rate estimates by Jernigan et $\mathrm{al}^{5}{ }^{5}$ for unrecognized or nonisolated MRSA carriers during the 21 -month study period, 0.42 days of transmission of MRSA would have occurred over the 3 patientdays not spent in isolation. It would therefore take 7,971 patient-days (3.99 years and 3,796 babies) to prevent one MRSA transmission-day, at the cost of $\$ 189,800$ for our healthcare system and $\$ 759,200$ for payers. We found no cases of MRSA bacteremia or invasive disease among term newborns less than 48 hours of age admitted to our nursery from January 1, 2006, through September 30, 2009.

Our study finds that MRSA colonization and infection of newborns at birth is extremely uncommon despite increasing incidence of CA-MRSA infections in our area. The transmission rates that we used for the newborns were derived from a study in a neonatal ICU and therefore may overestimate the MRSA transmission rate, because the characteristics of newborns in the nursery are different from those in the neonatal ICU. Our data suggest that universal screening of newborns for MRSA colonization appears unnecessary and not cost-effective for healthcare systems and payers in our geographic area at this time, on the basis of the low incidence of MRSA nasal colonization at birth, the short hospital stays of healthy newborns, and the absence of invasive MRSA infection in term newborns.

\section{ACKNOWLEDGMENTS}

Potential conflicts of interest. J.P.P. reports receiving an honorarium from Cepheid. P.S. reports being part of multiple studies funded by Cepheid. All other authors report no conflicts of interest relevant to this article.

Pankaj Chhangani, $\mathrm{MD} ;^{1}$ Ramon Durazo, $\mathrm{PhD}{ }^{2}$ Laura Digangi; ${ }^{3}$ Jorge P. Parada, MD, MPH; ${ }^{4}$ Paul Schreckenberger, PhD; ${ }^{5}$ Violet Rekasius; ${ }^{6}$ Malliswari Challapalli, MD $^{1}$
Affiliations: 1. Department of Pediatrics, Loyola University Medical Center, Maywood, Illinois; 2. Preventive Medicine and Epidemiology, Loyola University Chicago Stritch School of Medicine, Chicago, Illinois; 3. Office of Information Technologies, Loyola University Chicago Stritch School of Medicine, Chicago, Illinois; 4. Department of Medicine, Loyola University Medical Center, Maywood, Illinois; 5. Department of Pathology, Loyola University Medical Center, Maywood, Illinois; 6. Microbiology Laboratory, Loyola University Medical Center, Maywood, Illinois.

Address reprint requests to $\mathrm{M}$. Challapalli, MD, Department of Pediatrics, Maguire Building, Loyola University Medical Center, 2160 South First Avenue, Maywood, IL 60153 (mchalla@lumc.edu). Infect Control Hosp Epidemiol 2011;32(3):301-302

(C) 2011 by The Society for Healthcare Epidemiology of America. All rights reserved. 0899-823X/2011/3203-0019\$15.00. DOI: 10.1086/658915

\section{REFERENCES}

1. Laibl VR, Sheffield JS, Roberts S, McIntire DD, Trevino S, Wendel GD Jr. Clinical presentation of community-acquired methicillinresistant Staphylococcus aureus in pregnancy. Obstet Gynecol 2005; 106:461-465.

2. Andrews WW, Schelonka R, Waites K, Stamm A, Cliver SP, Moser S. Genital tract methicillin-resistant Staphylococcus aureus-risk of vertical transmission in pregnant women. Obstet Gynecol 2008; 111:113-118.

3. Chen KT, Huard RC, Della-Latta P, Saiman L. Prevalence of methicillin-sensitive and methicillin-resistant Staphylococcus aureus in pregnant women. Obstet Gynecol 2006;108:482-487.

4. Creech CB, Litzner B, Talbot TR, Schaffner W. Frequency of detection of methicillin resistant Staphylococcus aureus from rectovaginal swabs in pregnant women. Am J Infect Control 2010; 38:72-74.

5. Jernigan JA, Titus MG, Groschel DHM, Getchell-White SI, Farr BM. Effectiveness of contact isolation during a hospital outbreak of methicillin-resistant Staphylococcus aureus. Am J Epidemiol 1996;143:496-504.

6. Public act 095-0312. Illinois General Assembly, August 20, 2007. http://www.ilga.gov/legislation/publicacts/fulltext.asp? Name $=$ 095-0312. Accessed June 20, 2010. 